\section{Infektionen sicher meistern}

$B^{i}$ ei der Behandlung von Infektionserkrankungen wird es immer schwerer, neben neuen mikrobiologischen Erkenntnissen über die Entwicklung und Ausbreitung von Resistenzmerkmalen oder neben der Veränderung der lokalen und globalen epidemiologischen Situation, auch das ganze Repertoire der antiinfektiven Substanzen en detail für die klinische Anwendung präsent zu haben. Deshalb greifen nicht nur Berufsanfänger, sondern auch infektiologische Profis seit Jahren zum Kitteltaschenbuch-Klassiker „Antibiotika am Krankenbett“.
Die englische Ausgabe dieses Standardwerks bietet die bewährte schnelle und übersichtliche Orientierung zu den aktuellen Therapiestandards bakterieller und mykotischer Infektionen. Grundlegende Prinzipien der antiinfektiven Therapie werden dabei genauso kurz und bündig dargestellt wie das Wirkspektrum und die adäquate Dosierung der aktuell verfügbaren antimikrobiellen Substanzen. Wichtige Ergänzungen zur Verabreichung dieser Substanzen bei Nierenoder Leberinsuffizienz und während des Einsatzes von Nierenersatzverfahren fin-

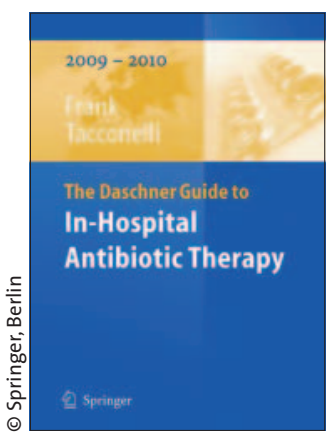

Frank U, Tacconelli E. The Daschner Guide to In-Hospital Antibiotic Therapy. Springer Berlin, 2009, 288 S., 21,35 EUR, ISBN 9783-540-48347-2

den genauso Beachtung wie die Therapie von Schwangeren. Darüber hinaus gehen die Autoren mit aktuellen Informationen detailliert auf die momentanen Resistenzsituationen in Europa ein.

$\mathrm{cl} / \mathrm{maw}$
Klemm E, Koch A, Hunger $S$. ... ich war 14 Tage lang geistig minderwertig: Ansichtskarten erzählen Krankenhausgeschichte, Dresden, 2009, 81 S., 9,50 EUR Eckhard Klemm, Chefarzt der HNOKlinik, hat nun zusammen mit $\mathrm{Co}-\mathrm{Au}-$ toren ein interessant bebildertes Bändchen vorgelegt, in dem gesammelte Postkarten aus der "guten alten Zeit" präsentiert werden, die Patienten in den letzten 160 Jahren aus dem Krankenhaus Dresden-Friedrichstadt in alle Welt geschickt haben. Die Texte sind original übernommen und strahlen damit eine unmittelbare menschliche Wärme aus. Freude und Leid, Schmerz und Zuver-

sicht, Krieg und Frieden liegen dabei eng beisammen. Die Patientenschicksale lassen den Leser niemals unberührt und wecken unbedingtes Interesse für eine intensive Lektüre.

Verbunden ist der Kauf dieses Buches für jeden historisch interessierten Kollegen mit einem Spendenaufruf zur Restaurierung des bekannten Neptunbrunnens auf dem jetzigen Krankenhausgelände. Im Namen der Krankenhausleitung und vor allem der Mitarbeiter des Hauses wird um Unterstützung gebeten, diese einzigartige Brunnenanlage zu retten. Das vorgelegte Büchlein wird als Dankeschön dienen, getreu den Worten eines betroffenen Patienten: „... ich muss noch einmal geschunden werden“. Das in limitierter Auflage von 1.500 Exem-

\title{
Wenn Anatomie lebendig wird
}

Clbst wenn Sie dieses Büchlein weder kaufen noch lesen: Seinem Gegenstand, der Anatomie, entgehen Sie nicht, denn Sie haben eine, auch wenn sich der Geist der Anatomie leider aus manchem Hörsaal verflüchtigt hat. Zugegeben: Es handelt sich um einen durchaus widerborstigen Geist, der sich in mitunter respektlosem Ton seinen Gegenständen nähert.

Dies ist weder ein Anatomielehrbuch noch bloße Anekdotensammlung, vielmehr ein Buch, das in leichtem Ton und mit Klugheit von Menschen, der Entstehung anatomischer Erkenntnisse, Schönheit, Philosophie und von Leben und Tod erzählt. Um der Lektüre des Buches nicht überdrüssig zu werden, sollten Sie zweierlei mitbringen. Erstens das Vermögen, Vergnügen zu empfinden, wenn Geist und Sprache Volten schlagen. Zweitens das Vermögen, kreuz und quer zu lesen. Denn es sind lauter einzelne Geschichten, und die besten stehen stets weiter hinten. Ein Vermögen müssen Sie dafür nicht aufbringen: Es kostet ja nicht die Welt. Doch

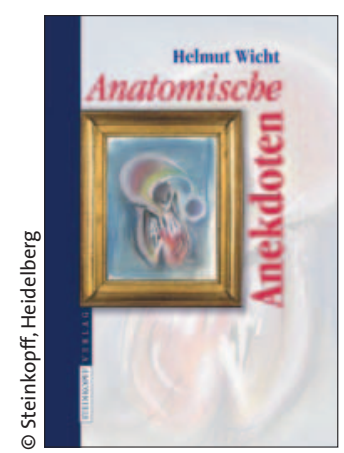

Wicht $\mathrm{H}$. Anatomische Anekdoten. Steinkopff, Heidelberg, 2010, 102 S., 16,95 EUR, ISBN 978 3-7985-1897-1

wenn Buch und Leser zusammenpassen, könnte es Ihnen eine eröffnen. red 